\title{
EFFECT OF SURFACE MODIFICATION ON MECHANICAL PROPERTIES OF QUARTZ FIBER REINFORCED BORON DOPED SILICONE RESIN COMPOSITES
}

\author{
Changqing $\mathrm{Yu}^{1,2, a}$, Yuchen Pei ${ }^{2, \mathrm{~b}}$, Li Chen ${ }^{1, \mathrm{c},{ }^{*}}$ \\ ${ }^{1}$ Key Laboratory of Advanced Textile Composites, Tianjin Polytechnical University, Tianjin , 300387 , \\ People's Republic of China \\ ${ }^{2} 306$ Institute, The Third Academy of China Aerospace Science \& Industry Corp., Beijing 100000, \\ People's Republic of China \\ ayuchangqing1980@163.com, ${ }^{\mathrm{b}}$ 5120303817@163.com, ${ }^{\mathrm{x} x i a l o n g}$ aron@163.com
}

\begin{abstract}
Keywords: Silicones; Composites; Thermal properties; Mechanical properties.
\end{abstract}
Abstract. 3-triethoxysilylpropylamine (KH550) polymer was coated on quartz fibers by a simple dipping process without any complex chemical treatments in order to increase the bonding strength between quartz fibers and boron doped silicone resin matrix. The effect of coating on the interface of quartz fiber reinforced composites was evaluated by scanning electron microscope (SEM), FTIR, DTA-TG and flexural strength of unidirectional composites. Results indicated that the coating played an important role in improving the interfacial adhesion and thermal stability of quartz fibers composites. The FTIR result showed that Si-O-B bonds in silicone resin chain decomposed when the heat treatment temperature increased to $500^{\circ} \mathrm{C}$. The composites with $\mathrm{KH} 550$ coatings exhibited better room temperature and high temperature flexural strength than those of the composites without KH550 coatings.

\section{Introduction}

Silicone resin is one kind of ideal materials to fabricate radome and windows of antenna due to its high thermal shock resistance and low thermal expansion as well as excellent dielectric properties. ${ }^{[1-4]}$ Nevertheless, the low strength and low decomposition temperature of silicone resin are the vital factors that hinder their practical application as structure materials at high temperature.

It is common to do some modifications on the main chain of silicone resins, in order to improve their thermal resistant properties. Some inorganic elements, such as B, Ti, Al, $\mathrm{Sn}$ and $\mathrm{Pb}$, have been introduced into the silicone backbone. ${ }^{[5-9]}$ The modification silicone resins demonstrate excellent thermal stability because of the high bonding energy between doping elements and oxygen. For example, the covalent bond energy of $\mathrm{B}-\mathrm{O}$ bond is $514 \mathrm{~kJ} / \mathrm{mol}$, which is higher than that of Si-O bond $(451 \mathrm{~kJ} / \mathrm{mol}) .{ }^{[10]}$

The low mechanical performance of silicone resin can be improved by the addition of second phase. Quartz fibers (Qf) have demonstrated a wide range of attributes including high strength and low density for structural application. Most importantly, quartz fibers have low dielectric constant and loss, which facilitate to the increase in electromagnetic wave transparent in the composites. However, smooth surface and chemical inert nature of the quartz fiber only bring a weak adhesion to the matrix. In the carbon fiber reinforce epoxy resin composites, carbon fibers are usually modified by the surface treatment to improve its surface wettability or to increase the roughness of its surface, in order to achieve a good adhesion on the interface between the reinforcement and the matrix. Up to now, many efforts have been devoted to modify carbon fibers for improving the interfacial properties between the carbon fibers and the matrix, such as plasma treatment, ${ }^{[11-13]}$ radiation treatment, ${ }^{[14,15]}$ chemical modifications. ${ }^{[16-18]}$ In contrast, little work has been done to modify the surface of quartz fibers.

The sizing agent is one of the simple and efficient approaches that can increase the reactivity between fibers and matrix by enhancing the physical and chemical properties of the fiber surface. Also, the sizing agent is beneficial to improve the wettability of the fiber surface to the matrix resin in the process of composing. ${ }^{[19-23]}$ 
In this work, 3-triethoxysilylpropylamine (KH550) polymer was utilized as an adhesive fiber-surface modifier to increase the interfacial strength of fiber-reinforced composites by providing an additional chemical interaction with silicone resin. KH550 polymer has hydrogen-containing functional groups and secondary amine, which can establish hydrogen bonds with many sites in the silicone resin and increase the degree of cure. Consequently, KH550 can effectively increase the interfacial strength of the composites.

The objective of this study is to investigate the effect of KH550 on the surface of quartz fibers, which increase the quantity of chemical groups on the surfaces of quartz fibers. The final aim is to increase mechanical performance of the quartz fibers reinforced composites. The effect of surface treatment method on the microstructure, flexural strength and thermal decomposition of composites is investigated.

\section{Experimental}

\section{Preparation of materials}

Boron doped silicone resin (BSR) were synthesized by reacting boric acid with methyltriethoxysilane (MTES) in the presence of $\mathrm{HCl}$. In a typical reaction, a mixture containing 9.27 $\mathrm{g}(0.15 \mathrm{~mol})$ of boric acid with $80.24 \mathrm{~g}(0.45 \mathrm{~mol})$ of MTES and $1 \mathrm{~mL}$ of concentrated hydrochloric acid were taken in a three necked round bottom flask equipped with a mechanical stirrer and an inlet and outlet for nitrogen. Solutions were prepared at $70{ }^{\circ} \mathrm{C}$ by stirring the MTES with the boric acid under reflux in nitrogen gas until complete dissolution. The condensation reaction between $\mathrm{Si}-\mathrm{OH}$ and $\mathrm{Si}-\mathrm{OH}$ or $\mathrm{B}-\mathrm{OH}$ took place, generating an appropriate degree of cross-linking within silicone resin. ${ }^{[24-28]}$

The quartz fibers used in the study was supplied by Hubei Feilihua quartz glass Co., LTD. The density was $2.2 \mathrm{~g} . \mathrm{cm}^{-3}$ and the diameter of fiber was $7.5 \mu \mathrm{m}$. The size agent of KH550 was prepared by mixing $2 \mathrm{~g} \mathrm{KH} 550$ with $50 \mathrm{ml}$ ethanol (AR.). Quartz fibers were dipped into solution for $10 \mathrm{~min}$ and then dried at $60^{\circ} \mathrm{C}$ for $1 \mathrm{~h}$. This dip-dried process was repeated 3 times, in order to obtain coatings with good surface.

Quartz fiber tows were carefully guided through a tank containing the as-prepared boron doped silicone resin. The boron doped silicone resin impregnated quartz fiber tows were wound on to a hexagonal drum in an aligned arrangement. After the impregnation, the fiber sheets were cut into the desired size. Unidirectional quartz fiber reinforced boron doped silicone resin matrix (Qf/BSR) composites were prepared by stacking the fiber sheets into a steel mould and the detailed curing procedure was illustrated in Fig. 1. The content of quartz fiber was approximate $45 \sim 50$ vol\%. The as produced composites using quartz fibers with and without surface modification were denoted as Qf/BSR-KH550 and Qf/BSR, respectively.

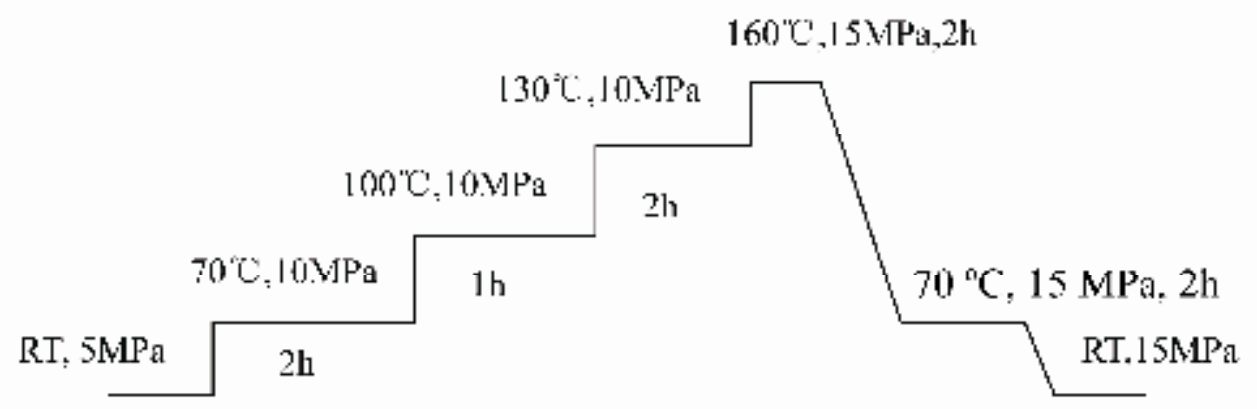

Fig 1. Curing process of Qf/BSR and Qf/BSR-KH550 composites

\section{Characterization}

The observation of microstructure of the as-prepared composites was carried out with scanning electron microscope (SEM, Vega, Tescan, Czech). The phases in the samples were identified by X-ray diffractometer (XRD, D/max $-\gamma \mathrm{B}$, Rigaku, Japan). FTIR of the specimens was performed with Nicolet 
380 FTIR spectrometer using $\mathrm{KBr}$ pellete technique in the wave number range $400-4000 \mathrm{~cm}^{-1}$. The thermal decomposition behavior of Qf/BSR-KH550 and Qf/BSR composites were characterized by differential thermal analysis (DTA) and thermogravimetry (TG) (Netzsch STA 409c) from 30 to $1000{ }^{\circ} \mathrm{C}$ in air atmosphere at the heating rate of $10^{\circ} \mathrm{C} / \mathrm{min}$.

The flexural strength was measured by three-point-bending tests on $3 \mathrm{~mm}$ by $4 \mathrm{~mm}$ by $36 \mathrm{~mm}$ bars at a cross-head speed of $0.5 \mathrm{~mm} \mathrm{~min}^{-1}$ and a span of $30 \mathrm{~mm}$. The value of the flexural strength was estimated as:

$$
\sigma_{f}=\frac{3 P L}{2 b d^{2}}
$$

where $P$ is the maximum applied load, $b$ and $d$ are the width and thickness of the specimen respectively and $L$ is the span of the bending specimen. At least five specimens were prepared and tested for each type of composites.

The residual flexural strength test was carried out in static air in an alumina tube furnace at room temperature, $200{ }^{\circ} \mathrm{C}, 400{ }^{\circ} \mathrm{C}$ and $600{ }^{\circ} \mathrm{C}$ for $0.5 \mathrm{~h}$, separately. There were five samples tested at each specific temperature for every kind of specimen. The specimen was directly pushed into the furnace for heat treatment when the furnace was heated up to the given temperature, and pulled out from the tube furnace after the given time, then cooled to room temperature in air for flexural test.

\section{Results and discussion}

\section{Structural characteristics of boron doped silicone resin}

XRD spectra are presented in Fig. 2. As can be seen, only a broad peak is seen around a diffraction angle of about $22^{\circ}$ for these bulk samples, indicating their amorphous structure. The XRD result suggests that the boric acid reacts with MTES completely because no peaks of the residual boric acid have been detected.

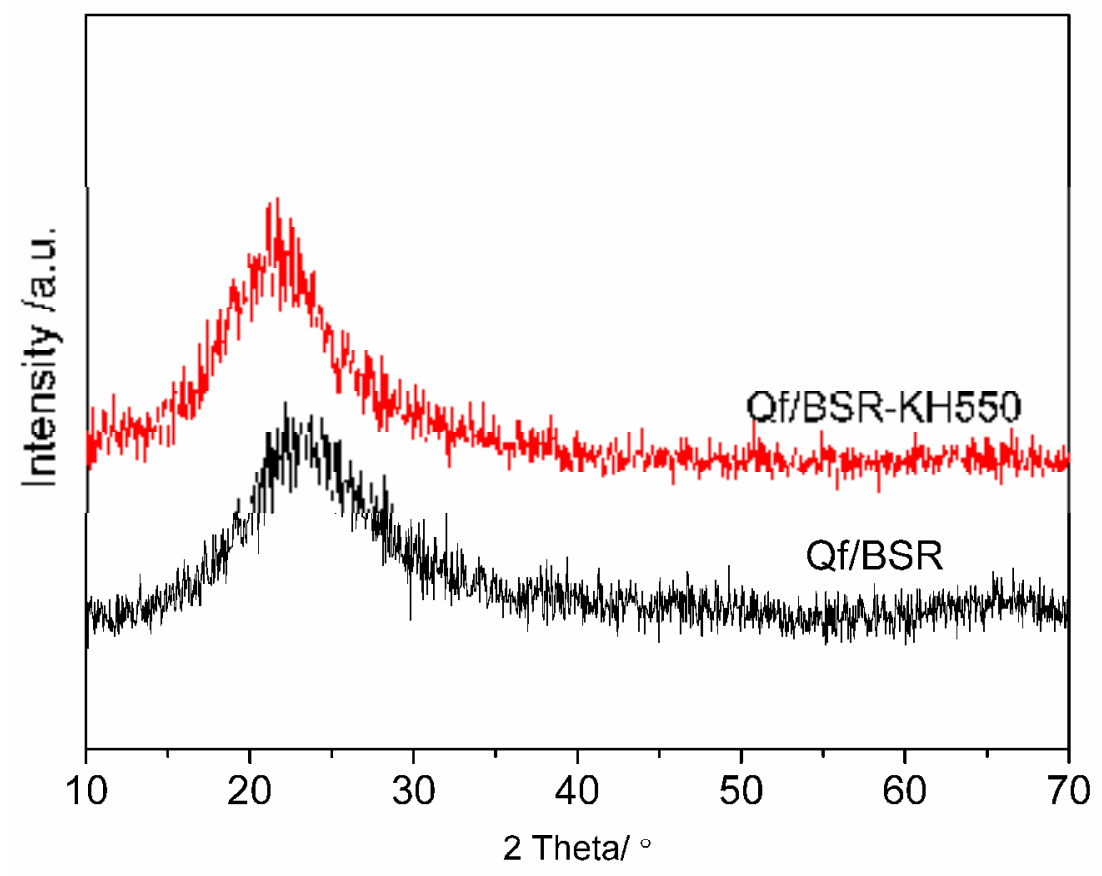

Fig 2. XRD spectra of Qf/BSR and Qf/BSR-KH550.

To investigate the structural changes occurred towards the formation of boron doped silicone resin in the specimens, FTIR studies are performed in the wave number region range of $4000-400 \mathrm{~cm}^{-1}$. As shown in Fig 3, curves A and B represent the FTIR spectra of the Qf/BSR and Qf/BSR-KH550 composites, respectively. A strong broad band in the wave number region around $3430 \mathrm{~cm}^{-1} \mathrm{can}$ be 
observed in all specimens. This band can attribute to stretching vibration of hydroxyl group. The absorption bands of 2972 and $2914 \mathrm{~cm}^{-1}$ are assigned to the anti-symmetry and symmetry stretching vibration of $\mathrm{C}-\mathrm{H}$ from $-\mathrm{CH}_{3}$ or $-\mathrm{CH}_{2}-\mathrm{CH}_{2}-\mathrm{CH}_{3}$. ${ }^{[29,30]}$

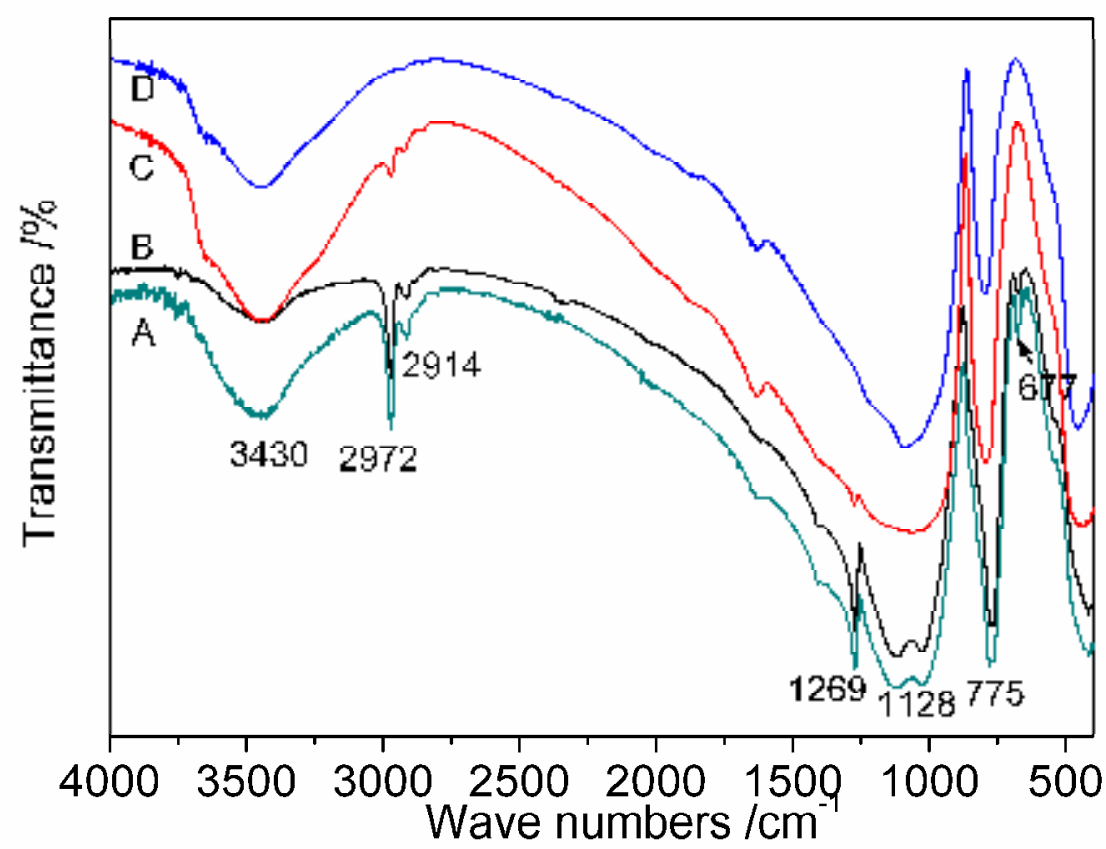

Fig 3. FTIR spectrogram of Qf/BSR (curve A), Qf/BSR-KH550 (curve B), Qf/BSR-KH550 heat treated at $500^{\circ} \mathrm{C}$ (curve C) and Qf/BSR-KH550 heat treated at $600^{\circ} \mathrm{C}$ (curve D).

The absorption peak at $1269 \mathrm{~cm}^{-1}$ attributes to the stretching vibration of $\mathrm{Si}_{-} \mathrm{CH}_{3}$. The strong absorption peaks at 1128 and $1030 \mathrm{~cm}^{-1}$ are assigned to the anti-symmetry stretching vibration of $\mathrm{V}$ $\mathrm{Si}$-O-Si. A medium strong absorption band in the region $775 \mathrm{~cm}^{-1}$ appeared in the specimens indicates the symmetry stretching vibration of $\mathrm{Si}-\mathrm{C}$ bond, which is the characteristic vibration of organic silicone resin. ${ }^{[31-33]}$

The absorption band at around $677 \mathrm{~cm}^{-1}$ corresponds to stretching vibration of B-O-Si. [34-36] This result suggests that boron atom has been successfully doped into the silicone resin chain in the form of Si-O-B bond by the method of hydrolysis-polycondensation. The characteristic absorption peaks of KH550 are not obvious in curve B because of trace amount of KH550 existing in Qf/BSR-KH550 composites.

The Qf/BSR-KH550 composites were pyrolyzed in a tube furnace under air at different temperatures up to $600{ }^{\circ} \mathrm{C}$. The evolution of the FT-IR spectra recorded on these samples is reported in Fig 3, in order to investigate the thermal degradation mechanism of Qf/BSR-KH550. When compared curves B, C and D, the notable difference among them is that the absorption peaks of C-H at $2972 \mathrm{~cm}^{-1}$ and $2914 \mathrm{~cm}^{-1}$ in curve B decrease with rising heat treatment temperature beyond $500^{\circ} \mathrm{C}$. The absorption peak of $\mathrm{B}-\mathrm{O}-\mathrm{Si}$ at $677 \mathrm{~cm}^{-1}$ in curve $\mathrm{B}$ almost disappears in curves $\mathrm{C}$ and $\mathrm{D}$, indicating the thermal degradation of Si-O-B bonds of the main chains. It is also seen, from Figs 3, that the absorption peak of $\mathrm{Si}-\mathrm{CH}_{3}$ at $1269 \mathrm{~cm}^{-1}$ nearly disappears at $600^{\circ} \mathrm{C}$, suggesting the decomposition of the organic $\mathrm{CH}_{3}$ moieties.

\section{DTA-TG analysis}

Fig. 4a and 4b show the curves of the DTA-TG analysis of Qf/BSR and Qf/BSR-KH550 composites. The DTA curve of Qf/BSR shows an obvious exothermic peak at $351^{\circ} \mathrm{C}$ and a broad exothermic peak at $539^{\circ} \mathrm{C}$, respectively (Fig. 4a). The exothermic peak temperatures for the Qf/BSR-KH550 composites are observed at $433^{\circ} \mathrm{C}$ and $633^{\circ} \mathrm{C}$ (Fig. $4 \mathrm{~b}$ ). From the Qf/BSR TG curve, it is clear that the continuous weight loss starts at room temperature and lasts until $600^{\circ} \mathrm{C}$. 

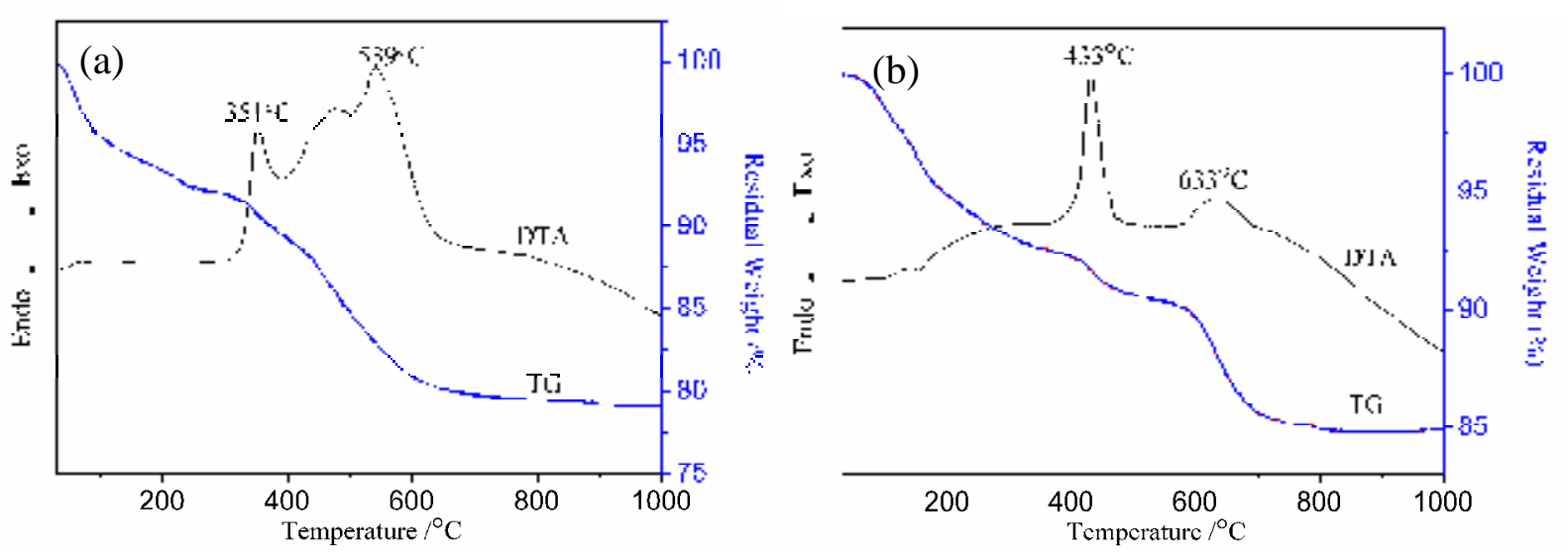

Fig 4. TG-DTA curves of (a) Qf/BSR and (b) Qf/BSR-KH550.

The weight loss of Qf/BSR-KH550 composites starts at room temperature with relatively low rate. From room temperature to $400^{\circ} \mathrm{C}$, the weight loss is associated to the evolution of water and ethanol molecules resulting from the residual $\mathrm{Si}-\mathrm{OH}$ and $\mathrm{Si}-\mathrm{OEt}$ groups present in the gels. The weight loss rate increases obviously when the temperature rises to $433^{\circ} \mathrm{C}$. Another rapid weight loss stage starts at $633^{\circ} \mathrm{C}$. It can be seen from the TG curves that the weight loss of Qf/BSR-KH550 is $15 \mathrm{wt} \%$ at $1000^{\circ} \mathrm{C}$, which is lower than that of Qf/BSR composites.

The small endothermic peaks of Qf/BSR at $351^{\circ} \mathrm{C}$ and Qf/BSR-KH550 at $433^{\circ} \mathrm{C}$ are assigned to the redistribution reactions between $\mathrm{Si}-\mathrm{O} / \mathrm{Si}-\mathrm{C}$ bonds leads to the evolution of low molecular weight siloxane species. ${ }^{[37,38]}$ The second endothermic peaks of Qf/BSR at $539^{\circ} \mathrm{C}$ and Qf/BSR-KH550 at around $633^{\circ} \mathrm{C}$ are attributed to the mineralization reactions take place with the hemolytic cleavage of $\mathrm{C}-\mathrm{H}$ and $\mathrm{Si}-\mathrm{C}$ bonds and the formation of $\mathrm{H}_{2}$ and $\mathrm{CH}_{4}$, accompanied by the thermal degradation of $\mathrm{Si}-\mathrm{O}-\mathrm{Si}$ and $\mathrm{Si}-\mathrm{O}-\mathrm{B}$ bonds of the main chains. ${ }^{[39,40]}$ The sizing agent of KH550 on the quartz fiber increases the thermal decomposition temperature of Qf/BSR-KH550 composites significantly. Synergetic effect between the strong bonding of interface and the increase of the degree of cure, contributes to the improvement of thermal stability of Qf/BSR-KH550 composites.

\section{Mechanical properties}

Fig. 5 shows the effect of the surface modification using KH550 on the flexural strength of Qf/BSR composites. For comparison, the flexural strength of Qf/BSR composites is also shown in Fig. 5. It can be seen that composites modified by KH550, possesses a higher flexural strength than the composite with as-received quartz fibers. That is to say, the flexural behavior of Qf/BSR-KH550 composites in this study is improved by the tailored fiber-matrix interface. The flexural strength decreases with increasing heat treatment temperature.

Typical stress-strain curves of the Qf/BSR and Qf/BSR-KH550 composites, recorded by the three-point bending test, are shown in Fig. 6. The curves of Qf/BSR and Qf/BSR-KH550 composites show elastic response in the initial stage. When the load reaches certain value marked as the open circle in this Fig, it drops off the elastic response gradually. The large areas under these curves indicate that abundant of fracture energy is exhausted and the toughness is improved prominently.

Load-displacement curves for Qf/BSR and Qf/BSR-KH550 composites heat treated at $600^{\circ} \mathrm{C}$ are shown in Fig. 6b. With increasing the load, the samples exhibit inelastic response, indicating occurrence of microcracks in the matrix. The non-linear response lasts until the maximum load, followed by an obvious drop in load, which is attributed to fiber bundle failure. The final stage is the non-linear region in the tail of curve, revealing fiber pull-out, bridging, and sliding. ${ }^{[41]}$ 


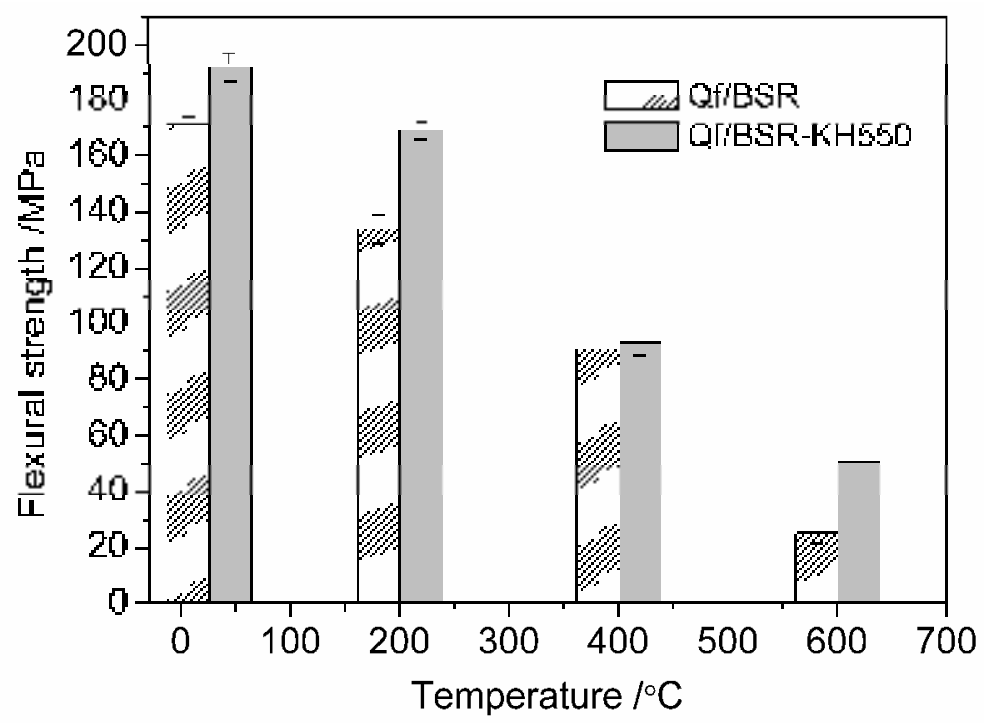

Fig 5. Flexural strength of Qf/BSR and Qf/BSR-KH550 at different temperatures.
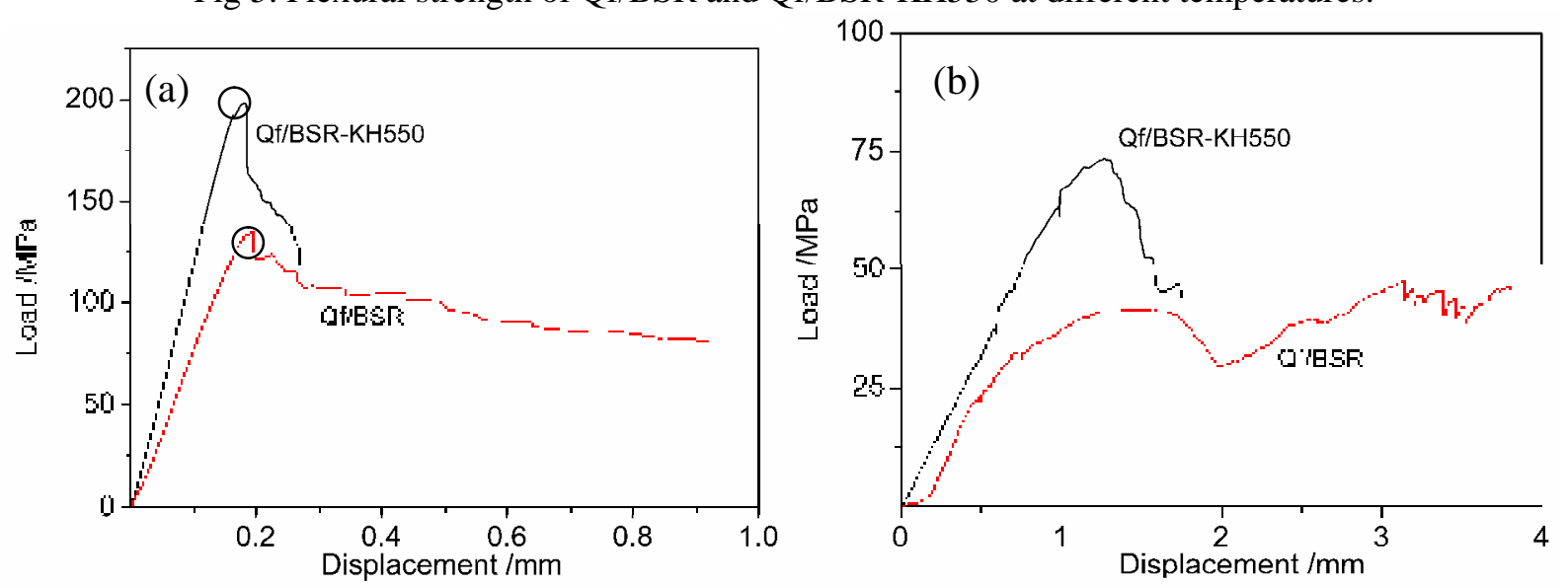

Fig 6. Comparison of three-point flexural curves of (a) Qf/BSR and Qf/BSR-KH550 composites and (b) Qf/BSR and Qf/BSR-KH550 composites heat-treated at $600^{\circ} \mathrm{C}$.

\section{Observation of fracture surface}

Fracture surfaces of the laminate specimens after tests were examined by SEM in order to further understand of the sizing agent on the carbon fiber interphase behavior. SEM photomicrographs of selected mid-plane fracture surfaces were shown in the Fig 7. The fiber pull-out is not observed evidently and some pores occur between the fiber and resin matrix of the unsized quartz fiber composites in the Fig 7. In contrast, the sized quartz fiber composites exhibits invisible boundary, which demonstrates relatively strong bonding between the fiber and the matrix (Fig 8). This is due to the fact that KH550 corresponds to some oxygenous functional groups, which lead to a better bonding between the quartz fiber and the boron doped silicone resin matrix. The strong bonding between the fiber and the matrix drastically affects the final mechanical properties of the composites through react and/or interact with the matrix by its functional groups. This interaction hinders the separation and pull out of fibers from the matrix. Thus, Qf/BSR-KH550 composites exhibit higher mechanical properties than Qf/BSR. 

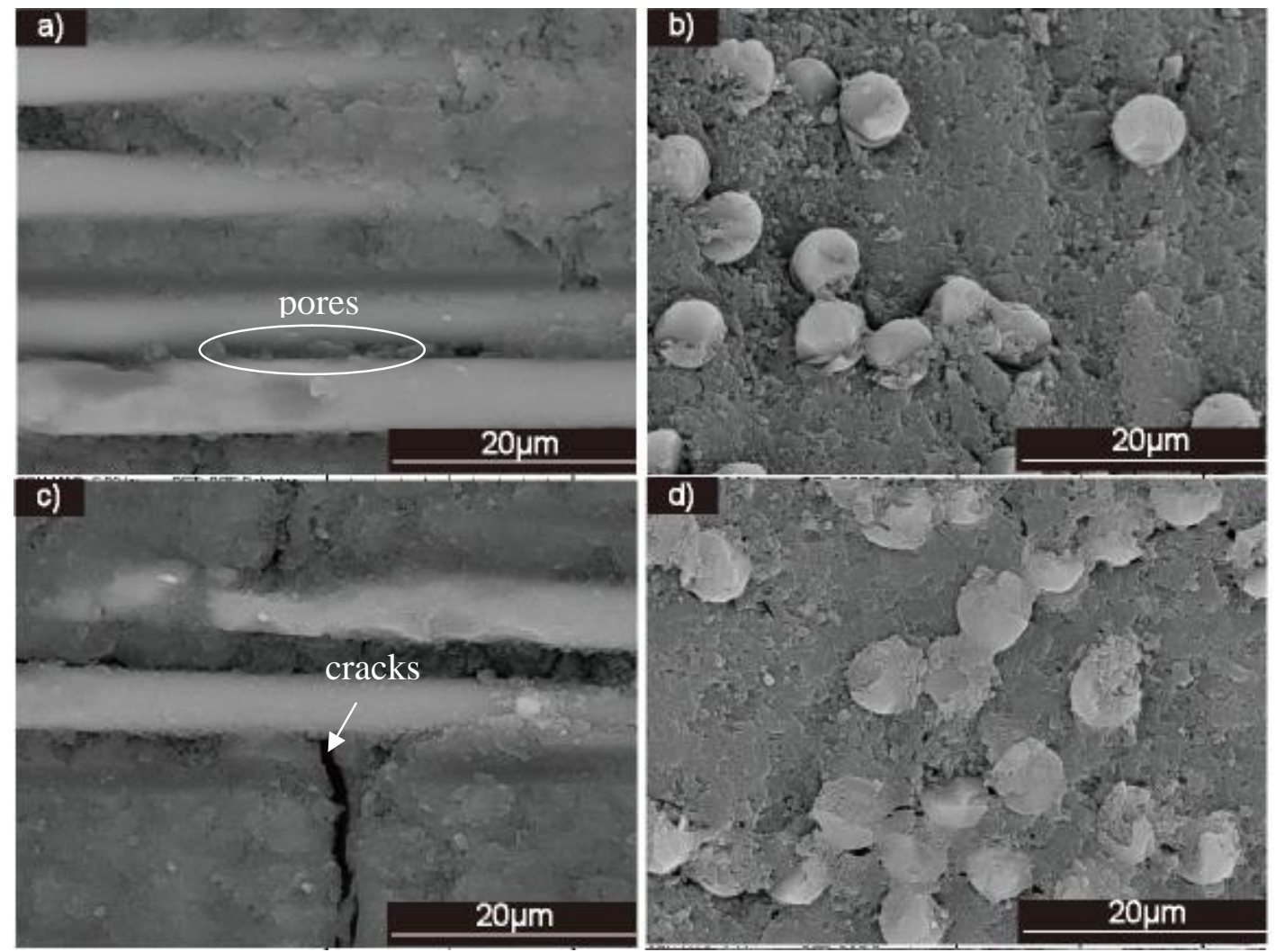

Fig 7. SEM images of Qf/BSR composites: (a) polished surface; (b) cross section and fractured surface of Qf/BSR composites after flexural test: (c) polished surface; (d) cross section.
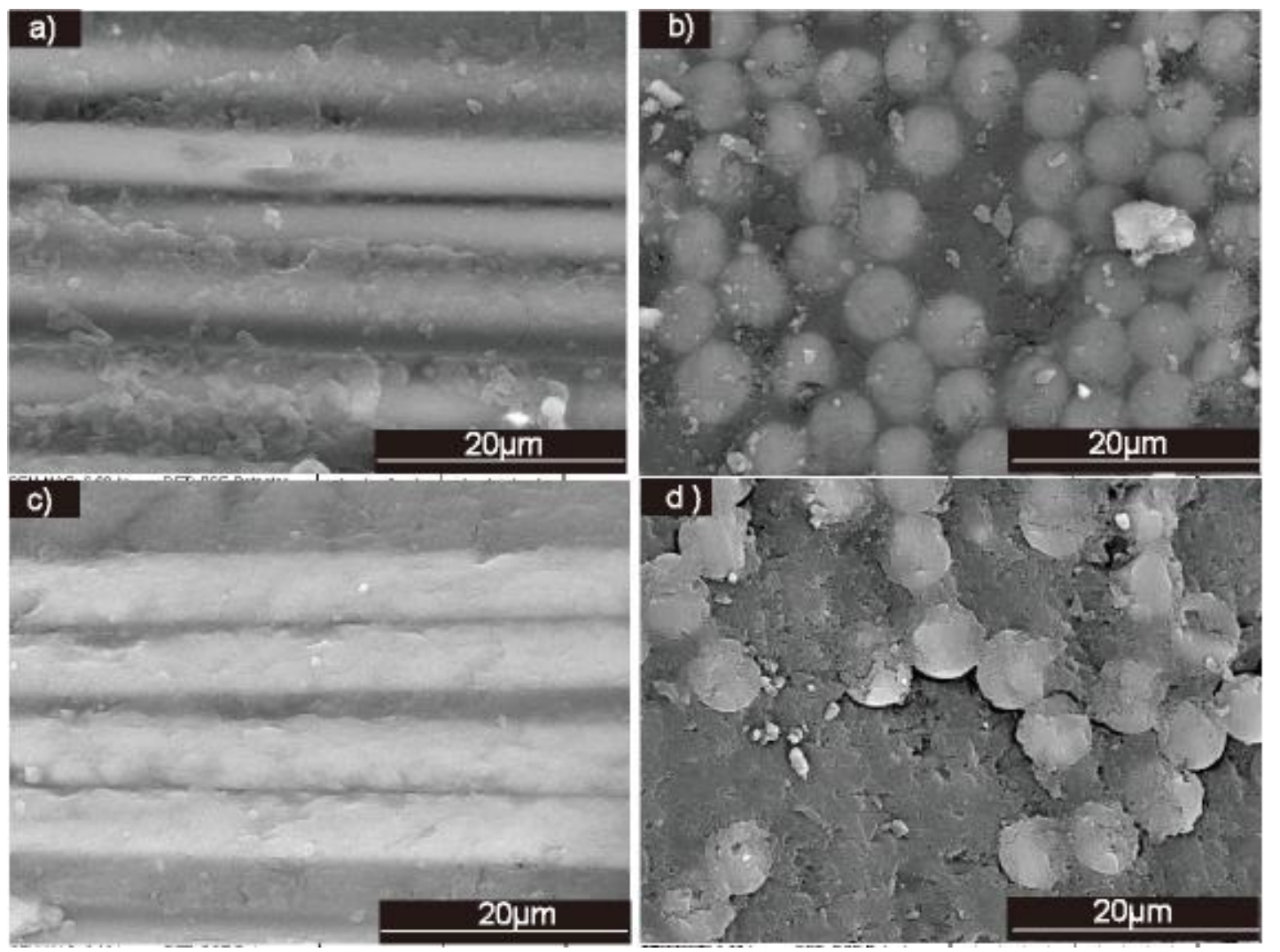

Fig 8. SEM images of Qf/BSR-KH550 composites: (a) polished surface; (b) cross section and fractured surface of Qf/BSR-KH550 composites after flexural test: (c) polished surface; (d) cross section. 


\section{Conclusions}

Quartz fiber reinforced boron doped silicone resin composites (Qf/BSR) were successfully fabricated by using impregnation and curing process. The effect of KH550 coating on the microstructure, flexural strength and thermal stability of the composite was studied in detail. The surface treatment of quartz fiber by KH550 increased room temperature and high temperature flexural strength significantly. The thermal degradation temperature of the Qf/BSR-KH550 composites was found to be much higher than that of Qf/BSR composites. Thermal stability and flexural strength of the Qf/BSR composites were reported to be closely related to the interfacial microstructure. The increase of bonding strength between the quartz fibers and silicone resin matrix and the increase of the degree of cure are believed to be the origin of the improved thermal stability and flexural strength of the Qf/BSR-KH550 composites.

\section{Acknowledgements}

This work was supported by the National Natural Science Foundation of China (51302050), the Fundamental Research Funds for the Central Universities (HIT. ICRST.2010009), the Natural Scientific Research Innovation Foundation in Harbin Institute of Technology (HIT.NSRIF.2014129), and the financial supporting from Yunshan Carbon Industry Co., Ltd.

\section{References}

1. Z. F. Chen, L. T. Zhang, L. F. Cheng, Y. D. Xu, and Z. H. Jin, "Effect of CVI Temperature on the Microstructure of Nextel 480/SiO ${ }_{2}$ ", Sci. Eng. Compos. Mater., 10, 403405 (2002).

2. C. M. Xu, S. W. Wang, X. X. Huang and J. K. Guo, "Processing and properties of unidirectional $\mathrm{SiO}_{2} \mathrm{f} / \mathrm{SiO}_{2}$ composites", Ceram. Int., 33, No. 4, 669-673 (2007).

3. N. E. Prasad, S. Kumari, S. V. Kamat, M. Vijayakumar, and G. Malakondaiah, "Fracture behavior of 2D-weaved, silica-silica continuous fiber-reinforced, ceramic-matrix composites(CFCCs)", Eng. Fract. Mech., 71, No. 18, 2589-2605 (2004).

4. N. E. Prasad, D. Loidl, and M. Vijayakumar, "Elastic properties of silica-silica continuous fibre-reinforced, ceramic matrix composites", Scr. Mater., 50, No. 8, 11211126 (2004).

5. P. Hajji, L. David, J. F. Gerard, J. P. Pascault and G. J. Vigier, "Synthesis, structure, and morphology of polymer-silica hybrid nanocomposites based on hydroxyethyl methacrylate", Polym. Sci. Part B: Polym. Phys., 37, 3172-3187 (1999).

6. X. M. Wang, Y. H. Wu, Z. F. Hao, J. Yu and L. Yu, "Preparation, Curing Reactivity and Thermal Properties of Titanium-doped Silicone Resins", Chem.Res. Chin. Univ., 26, 851-856 (2010).

7. Y. Wei, D. L.Jin, J. G. Xu, G. Baran and K. Y. Qiu, "Mechanical properties of interface - free polyacrylate - silica hybrid sol\&ndash;gel materials for potential dental applications", Polym. Adv. Technol., 12, 361-368 (2001).

8. K. H. Wu, T. C. Chang, Y. T. Wang and Y. S. Chiu, "Organic\&ndash; inorganic hybrid materials. I. Characterization and degradation of poly(imide\&ndash;silica) hybrids", J. Polym.Sci. Part A: Polym. Chem., 37, 2275-2284 (1999).

9. Z. K. Zhu, Y. Yang, J. Yin and Z. N. Qi, "Preparation and properties of organosoluble montmorillonite/polyimide hybrid materials", J. Appl. Polym. Sci., 73, 2063-2068 (1999).

10. X. Zhao, X. D. He, S. Zhang, L. D. Wang, M. W. Li and Y. B. Li, "Investigations on B-doped SiO2 thermal protective coatings by hybrid sol-gel method", Thin. Solid. Films., 519, 4849-4854 (2011).

11. C. U. Pittman, W. Jiang, G. R. He and S. D. Gardner, "Oxygen plasma and isobutylene plasma treatments of carbon fibers: Determination of surface functionality and effects on composite properties", Carbon., 36, 25-37 (1998).

12. H. Bubert, X. Ai and S. Haiber, "Basic analytical investigation of plasma-chemically modified carbon fibers", Spectroc. Acta Pt. B Atom. Spectr., 57, 1601-1610 (2002). 
13. J. I. Paredes, A. Martinez-Alonso and J. M. D. Tascon, "Atomic-scale scanning tunneling microscopy study of plasma-oxidized ultrahigh-modulus carbon fiber surfaces", J. Colloid. Interface. Sci., 258, 276-282 (2003).

14. Z. W. Xu, Y. D. Huang and C. H. Zhang, "Effect of $\gamma$-ray irradiation grafting on the carbon fibers and interfacial adhesion of epoxy composites", Compos. Sci. Technol., 67, 3261-3270 (2007).

15. J. Q. Li, Y. D. Huang and Z. W. Xu, "High-energy radiation technique treat on the surface of carbon fiber", Mater. Chem. Phys., 94, 315-321 (2005).

16. X. Chen, F. Mark and Y. M. Gao, "Mechanisms of surfactant adsorption on non-polar, air-oxidized and ozone-treated carbon surfaces", Carbon., 41, 1489-1500 (2003).

17. E. Pamula and P. G. Rouxhet, "Bulk and surface chemical functionalities of type III PAN-based carbon fibres", Carbon., 41, 1905-1915 (2003).

18. X. Z. Zhang, Y. Huang and T. Wang, "Influence of fibre surface oxidation-reduction followed by silsesquioxane coating treatment on interfacial mechanical properties of carbon fibre/polyarylacetylene composites", Compos. Pt. A-Appl. Sci. Manuf., 38, 936-944 (2007).

19. N. Dilsiz and J. P. Wightman, "Effect of acid-base properties of unsized and sized carbon fibers on fiber/epoxy matrix adhesion", Colloid. Surf. A., 164, 325-336 (2000).

20. K. J. Huttinger and G. Krekel, "Polydimethylsiloxane coated carbon fibres for the production of carbon-fibre reinforced carbon”, Carbon., 29, 1065-1070 (1991).

21. T. H. Cheng, J. Zhang and S. Yumitori, "Sizing resin structure and interphase formation in carbon fibre composites", Composites., 25, 661-670 (1994).

22. R. L. Zhang, Y. D. Huang and L. Liu, "Influence of sizing emulsifier content on the properties of carbon fibers and its composites", Mater. Des., 33, 367-371 (2012).

23. R. L. Zhang, Y. D. Huang and L. Liu, "Effect of the concentration of the sizing agent on the carbon fibers surface and interface properties of its composites", J. Appl. Polym. Sci., 125, 425-432 (2012).

24. Y. F. Liu, J. G. Gao and R. Z. Zhang, "Thermal properties and stability of boron-containing phenol-formaldehyde resin formed from paraformaldehyde", Polym. Degrad. Stab., 77, 495-501 (2002).

25. P. M. Barros, I. V. P.Yoshida and M. A, "Schiavon. Boron-containing poly(vinyl alcohol) as a ceramic precursor", J. Non-Cryst. Solids., 352, 3444-3450 (2006).

26. S. Mondal and A. K.Banthia, "Low-temperature synthetic route for boron carbide", J. Eur. Ceram. Soc., 25, 287-291 (2005).

27. I. Hasegawa, Y. Fujii, T. Takayama and K. Yamada, "Phenolic resin-boron oxide hybrids as precursors for boron carbide”, J. Mater.Sci. Lett., 18, 1629 -1631 (1999).

28. A. Sinha, T. Mahata and B. P.Sharma, "Carbothermal route for preparation of boron carbide powder from boric acid-citric acid gel precursor", J. Nucl. Mater., 301, 165-169 (2002).

29. C. Gervais, F. Babonnrau, N. Dallabonna and G. D. Soraru, "Sol-Gel-Derived Silicon-Boron Oxycarbide Glasses Containing Mixed Silicon Oxycarbide (Sicxo4-X) And Boron Oxycarbide (Bcyo3-Y) Units", J. Am. Ceram. Soc., 84, 2160-2164 (2001).

30. F. Guo, X. N. Xia, Y. Q. Xiong, J. Liu and W. J. Xu, "Novel macromolecular epoxy resin curing agent containing biphenyl and maleimide moieties: Preparation, curing kinetics, and thermal properties of its cured polymer", J. Appl. Polym. Sci., 125, 104-113 (2012).

31. N. Viart and J. L. Rehspringer, "Study of the action of formamide on the evolution of a sol by $\mathrm{pH}$ measurements and Fourier transformed infra-red spectroscopy", J. Non-Cryst. Solids., 195, 223-231 (1996).

32. R. Peña-Alonso, J. Rubio, F. Rubio and J. L. Oteo, “A FT-IR Study of the Synthesis of Boron Ormosils by Means of the Sol-Gel Process", J. Sol-Gel. Sci. Tech., 25, 255-263 (2002).

33. A. Kasgoz and T. Misono and Y. Abe, "Sol-gel preparation of borosilicates", J. Non-Cryst. Solids., 243, 168-174 (1999).

34. R. Peña-Alonso and G. D. Soraru', "Synthesis and characterization of hybrid borosiloxane gels as precursors for Si-B-O-C fibers”, J. Sol-Gel. Sci. Technol., 43, 313-319 (2007). 
35. M. Schiavona, N. Armelin, I. Valéria and P. Yoshida, "Novel poly(borosiloxane) precursors to amorphous SiBCO ceramics", Mater. Chem. Phys., 112, 1047-1054 (2008).

36. J. Shen, W. Jiang, Y. Liu, R. Q. Wei, X. N. Liu, Y. Zhong, J. Xu, L. L. Li, and G. Xue, "Synthesis and thermal properties of poly(methyl methacrylate)-poly(L-lactic acid)-poly(methyl-methacrylate) tri-block copolymer", J. Appl. Polym. Sci., 124, 3905-3911 (2012).

37. Z. F. Hao, J. Zhang, Y. H. Wu, J. Yu and L. Yu, "Synthesis and thermal stability properties of boron-doped silicone resin”, J. Appl. Polym. Sci., 131, 40934 (2014).

38. P. H. Mutin, "Role of Redistribution Reactions in the Polymer Route to Silicon-Carbon-Oxygen Ceramics", J. Am. Ceram. Soc., 85, No. 5, 1185-1189 (2004).

39. L. Pederiva, G. D. Soraru, J. Latourneire and R. Raj, "Pyrolysis Kinetics for the Conversion of a Polymer into an Amorphous Silicon Oxycarbide Ceramic", J. Am. Ceram. Soc., 85, 2181-2187 (2004).

40. G. D'Andrea, R. Campostrini and F. Babonneau, "Characterization of methyl-substituted silica gels with Si-H functionalities", J. Mater. Chem., 5, 1363-1374 (1995).

41. D. C. Jia, Y. Zhou, and T. Q. Lei, “Ambient and elevated temperature mechanical properties of hot-pressed fused silica matrix composite", J. Eur. Ceram. Soc., 23, 801-808 (2003). 